\title{
ESTUDO DAS TELAS CIRÚRGICAS DE POLIPROPILENO/ POLIGLECAPRONE E DE POLIPROPILENO/POLIDIOXANONA/ CELULOSE OXIDADA REGENERADA NA CICATRIZAÇÃO DE DEFEITO PRODUZIDO NA PAREDE ABDOMINAL DE RATOS
}

\author{
Study of surgical meshes of polypropylene/polyglecaprone and polypropylene/polydioxanone/ \\ oxidized regenerated cellulose on the healing of defects produced in abdominal wall of rats
}

Marcia Regina Zanello PUNDEK, Nicolau Gregori CZECZKO, Célia Toshie YAMAMOTO, Raul Fernando PIZZATTO, Leticia Elizabeth Augustin CZECZKO, Ulrich Andreas DIETZ, Osvaldo MALAFAIA

Trabalho realizado no Programa de PósGraduação em Princípios da Cirurgia do Hospital Universitário Evangélico de Curitiba/Faculdade Evangélica do Paraná, Curitiba, PR, Brasil.

DESCRITORES - Telas cirúrgicas. Aderências teciduais. Hérnia abdominal.

\section{Correspondência:}

Marcia Regina Zanello Pundek,

e-mail: zpmarcia@gmail.com

Fonte de financiamento: não há

Conflito de interesses: não há

Recebido para publicação: 03/11/2009

Aceito para publicação: 19/01/2010
RESUMO - Racional: O uso de telas cirúrgicas para a correção de defeitos da parede abdominal vem ocupando cada vez mais espaço nas operações no mundo todo. Objetivo: Estudar duas telas cirúrgicas distintas (Proceed ${ }^{\circledR}$ e Ultrapro ${ }^{\circledR}$ ) na cicatrização de defeito produzido em parede abdominal de ratos avaliando-se macroscopia, tensiometria e microscopia. Método - A amostra foi constituída por 32 ratos Wistar, divididos em dois grupos de 16 animais e quatro subgrupos de oito, submetidos à eutanásia com 15 dias e 30 dias para avaliação. As variáveis macroscópicas foram: presença de hematoma nos bordos da sutura da tela cirúrgica na parede abdominal, união entre a tela e a borda da ferida, presença de infecção no sítio cirúrgico, presença de fístulas de vísceras com a tela cirúrgica, presença de aderências dentro da cavidade abdominal e presença de hérnia incisional. Na microscopia avaliaram-se as fases do processo inflamatório da cicatrização, e na tensiometria a força tênsil necessária para ruptura do material. Resultados - A união entre a tela cirúrgica e a borda da ferida foi melhor no subgrupo Ultrapro 15 dias que no Proceed 15 dias; com 30 dias foi igual nos dois subgrupos. Não houve diferença significativa quanto às demais variáveis da macroscopia. Os dois grupos nos dois momentos tiveram a mesma proporção de casos com processo inflamatório crônico, mas houve maior escore de inflamação do Ultrapro 15 dias que do Ultrapro 30 dias. 0 subgrupo Ultrapro 15 dias mostrou força de ruptura maior que o subgrupo Proceed 15 dias, mas em 30 dias não houve diferença. Ultrapro mostrou força de ruptura igual para os dois momentos, mas Proceed 30 dias mostrou força de ruptura maior que Proceed 15 dias. Conclusão - As telas são semelhantes nas variáveis analisadas.

ABSTRACT - Background: The use of surgical meshes for the repair of abdominal wall defects has been increasing its share in surgeries worldwide. Aim - To study two different surgical meshes (Proceed ${ }^{\circledR}$ and Ultrapro ${ }^{\circledR}$ ) on the healing of defects produced in abdominal wall of rats evaluating the macroscopic, microscopic and tensiometric parameters. Method - Thirty two Wistar rats were divided into two groups of 16 animals and four groups of eight animals euthanized within 15 and 30 days for evaluation. The macroscopic variables were: the presence of hematoma at the edges of the sutures of the surgical mesh in the abdominal wall; the knitting of the surgical mesh and the edge of the wound; presence of infection at the surgical site; presence of viscera fistulas on the surgical mesh; presence of adhesions in the abdominal cavity; presence of incisional hernia. During microscopy the stages of the inflammatory process of healing where evaluated, and tensiometry evaluated the tensile force required to rupture the material. Results - The knitting of the mesh and the edge of the surgical wound was better in the 15 days Ultrapro subgroup than in the 15 days Proceed subgroup; within 30 days the knitting was similar in both subgroups. There was no significant difference for the variable of macroscopy. Both groups in both periods had the same proportion of cases with chronic inflammation, but there were higher scores of inflammation in the 15 days Ultrapro subgroup than the 30 days Ultrapro subgroup. The subgroup 15 days Ultrapro showed greater rupture strength than the subgroup 15 days Proceed, but in 30 days there were no difference. Ultrapro showed equal rupture strength in both periods, but 30 days Proceed showed greater rupture strength than 15 days Proceed. Conclusion - The meshes are similar in variables.
HEADINGS - Surgical Mesh. Tissue Adhesions. Hernia, abdominal. 
A história da cirurgia mostra que desde antes do nascimento de Cristo até hoje, os materiais de síntese, nós, aparelhos de anastomose com sutura mecânica e telas cirúrgicas têm sido indispensáveis para se conseguir a aproximação dos bordos de uma ferida, enquanto se processa a cicatrização. Por serem componentes externos, estes elementos causam reação nos tecidos, podendo variar desde processo exsudativo, reação de granuloma tipo corpo estranho, até resposta imunológica de hipersensibilidade do paciente.

Diferentes tipos de telas têm sido usados com uma frequência crescente na prática cirúrgica com as mais variadas indicações. Estas telas podem ser divididas em: absorvíveis e não-absorvíveis ou parcialmente absorvíveis. As telas absorvíveis (ácido poliglicólico, poligalactina e outras) são usadas para prevenção de injúria intestinal na radioterapia, para esplenorrafia, renorrafia, tratamento de prolapso retal, reparo de hérnia esofagiana e para hemostasia em órgãos. As telas não-absorvíveis ou parcialmente absorvíveis (Prolene ${ }^{\circledR}$, Mersilene ${ }^{\circledR}$, Vypro $^{\circledR}$, Ultrapro ${ }^{\circledR}$ e outras) são usadas para reparo de diferentes defeitos de parede abdominal. A tela cirúrgica, por não ser material próprio do corpo humano, deve ser idealmente separada das vísceras abdominais pela interposição do peritônio parietal, evitando assim aderências com os órgãos intra-abominais. Quando existem grandes defeitos da parede abdominal não é possível aproximar a parede abdominal e utilizar o peritônio para separar as vísceras da tela cirúrgica. Neste caso, é preciso colocar a tela intraperitoneal. Todas funcionam como corpos estranhos, sendo uma causa importante de formação de aderências peritoneais 20 .

Estudos experimentais vêm sendo realizados com diferentes telas cirúrgicas para que se obtenha uma mais próxima do ideal. Já em 1980 trabalho experimental estudou o comportamento das telas cirúrgicas na cavidade peritoneal ${ }^{28}$. Em 1983, também foram realizados estudos com diferentes telas cirúrgicas em animais com a finalidade de obter uma tela de composição ideal20. Estudos recentes perpetuam estudos experimentais para incrementar o conhecimento e compreensão dos efeitos das telas cirúrgicas na correção de defeitos da parede abdominal ${ }^{13,3,24,25,26}$.

Este estudo randomizado, prospectivo e transversal objetiva avaliar o processo de cicatrização em defeito produzido na parede abdominal ventral de ratos, comparando-se a tela de polipropileno/poliglecaprone com a de polipropileno/polidioxanona/celulose oxidada regenerada, estudando-se no $15^{\circ}$ dia e no $30^{\circ}$ dia pósoperatório, avaliando-se: 1 . o aspecto macroscópico da cicatrização; 2. o teste de resistência à tensão de rompimento do tecido cicatrizado e 3. a reação microscópica.
A amostra foi constituída de 32 ratos, os quais foram pesados e divididos de forma randomizada em dois grupos. No primeiro, foi utilizada uma tela monofilamentar de polipropileno e poliglecaprone (Ultrapro ${ }^{\circledR}$, Johnson\&Johnson, USA), enquanto no segundo a tela de polipropileno e polidioxanona (Proceed $^{\circledR}$, Johnson\&Johnson, USA). Cada grupo animal foi denominado pelo nome da tela, sendo os grupos subdivididos em dois subgrupos, Ultrapro/ Proceed 15 $(n=8)$ no qual os ratos foram submetidos à eutanásia aos 15 dias do pós-operatório, e Ultrapro/Proceed $30(n=8)$ com eutanásia aos 30 dias do pós-operatório.

Os animais após a indução anestésica com isofluorano receberam cloridrato de xilazina $2 \%$ e $100 \mathrm{mg} / \mathrm{kg}$ de cloridrato de ketamina $10 \%$ intramuscular. Foram posicionados em decúbito dorsal e realizou-se a tricotomia. O procedimento cirúrgico foi iniciado com uma incisão longitudinal mediana da parede abdominal com bisturi, com posterior descolamento da pele e tecido subcutâneo da aponeurose e do músculo reto abdominal. Então, utilizando um molde metálico de $1,0 \times 1,5 \mathrm{~cm}$ foi produzido um defeito da parede abdominal contendo aponeurose, músculo e peritônio parietal, sobre a linha Alba (Figura 1). As telas foram recortadas utilizandose molde metálico de 1,5 x 2,0 cm e fixadas com fio de polipropileno $n^{\circ} 4-0$ sobre o defeito produzido. A síntese da pele foi feita com sutura intradérmica com fio de prolipropileno $n^{\circ}$ 3-0 (Figura 2).

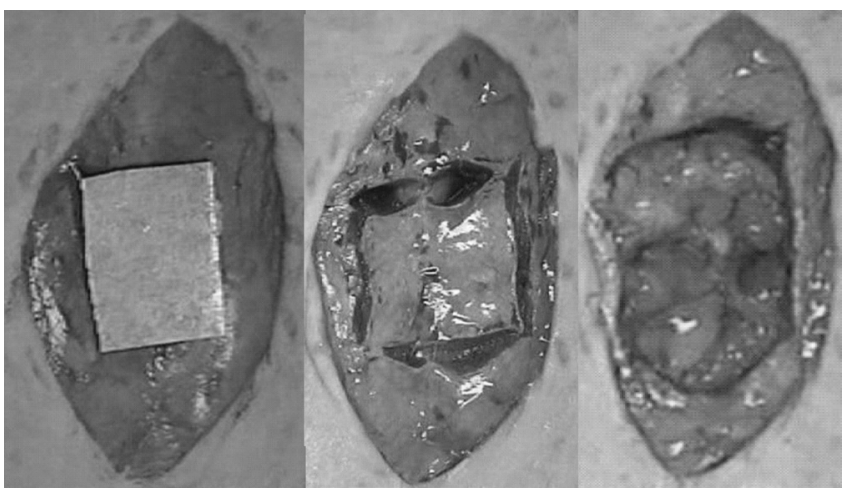

FIGURA 1 - Produção do defeito na parede abdominal

Os animais sofreram eutanásia no $15^{\circ}$ ou $30^{\circ}$ dia de pós-operatório em uma câmara de gás $\left(\mathrm{CO}^{2}\right)$, e procedeu-se a avaliação macroscópica. Os tecidos da parede abdominal com a tela cirúrgica foram ressecados e separados longitudinalmente em duas partes iguais. Um fragmento foi colocado em frasco com soro fisiológico com a identificação do animal e encaminhado à prova de tensão de ruptura (tensiometria - medidas de valor em Newton $/ \mathrm{cm}^{2}$ ). O outro fragmento foi estendido sobre uma tira de cartolina e colocado em frasco com solução de 


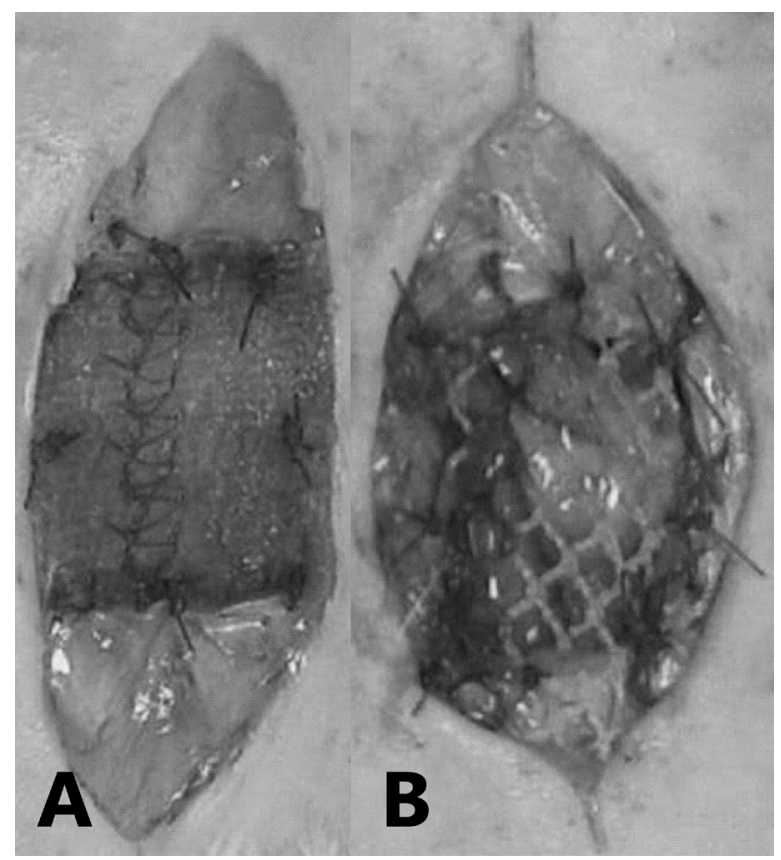

FIGURA 2 - A - sutura da tela no grupo Proceed; B - sutura da tela Ultrapro no defeito da parede abdominal

formaldeído e então encaminhado ao laboratório para avaliação histológica.

A tensiometria consistiu na avaliação da medida de deformidade máxima do tecido e da tensão de ruptura em Newton $/ \mathrm{cm}^{2}$ usando um extensômetro EMIC DL30000N. A peça cirúrgica foi presa nas duas extremidades próximas à sutura do tecido com a tela cirúrgica nas garras do aparelho e foi submetida à força tênsil com uma célula de carga de $50 \mathrm{Kg}$, submetida à tensão constante com velocidade de aceleração de 5 $\mathrm{mm} /$ minuto, até a ruptura do material (Figura 3). Todo o procedimento foi registrado no microcomputador em gráfico através do programa Tesc versão 1.10 onde se pôde demonstrar o valor em $\mathrm{N} / \mathrm{cm}^{2}$ da força alcançada no momento da deformação e ruptura.

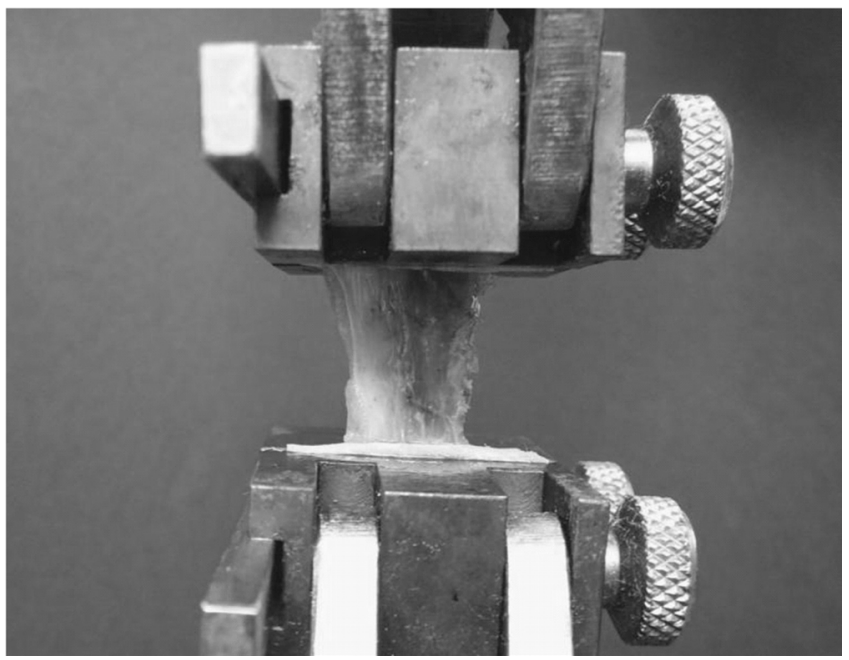

FIGURA 3 - Fragmento tecidual fixo no tensiômetro sendo submetido à análise de ruptura
Macroscopicamente foi avaliada a cicatrização através de análise clínica, através dos seguintes critérios: a) presença de hematoma no local de fixação da tela cirúrgica na parede abdominal: grau 0 = ausente e grau $1=$ presente; $b$ ) união entre a tela cirúrgica e a borda da ferida abdominal: grau 0 = unidas; grau 1 = deiscência parcial e grau 2 = deiscência total; c) presença de infecção no sítio cirúrgico sendo: grau 0 = ausente; grau 1 = infecção discreta e grau 2 = abscesso; d) presença de fístulas de vísceras com a tela cirúrgica: grau $0=$ ausente e grau 1= presente; e) presença de aderências dentro da cavidade abdominal22: grau 0 = ausência completa de aderências; grau 1 = aderência única entre dois órgãos ou entre um órgão e a parede abdominal; grau 2 = duas aderências entre órgãos entre si ou entre órgão e a parede abdominal; grau 3 = mais de duas aderências entre órgãos entre si ou com a parede abdominal; ou uma massa de aderências generalizada do intestino sem aderir à parede abdominal; grau 4 = aderências generalizadas entre órgãos e a parede abdominal; f) presença de hérnia visceral: grau $0=$ ausente e grau $1=$ presente.

A avaliação microscópica iniciou com o preparo das lâminas, para as quais o material foi fixado, desidratado e incluso em parafina, assim encaminhado para microtomia e após secagem coradas com hematoxilina e eosina. O estudo histológico foi realizado em microscópio Nikon modelo Eclipse E400, trinocular, acoplado a câmera de vídeo digital Samsung para obtenção das imagens e captura das imagens pelo software Laudo \& Imagem. Os parâmetros usados para se caracterizar a fase do processo inflamatório no $15^{\circ}$ e no $30^{\circ}$ dia do pós-operatório foram 30: a) tipo e quantidade das células predominantes na reação inflamatória (infiltrados poli e monomorfonuclear); b) presença de edema intersticial; c) congestão vascular; d) grau de formação de tecido de granulação; e) grau de formação de fibrose.

Os dados foram classificados em acentuado, moderado, discreto e ausente, de acordo com a intensidade em que foram encontrados, e transformados em variáveis quantitativas através da atribuição de índice aos achados histológicos. O edema, a congestão e o exsudato neutrofílico foram indicativos de processo inflamatório agudo, e receberam um sinal negativo; já o tecido de granulação, a fibrose e o exsudato monomorfonuclear foram indicativos de processo inflamatório crônico e receberam sinal positivo. Em seguida, somaram-se os índices encontrados para cada grupo, obtendo-se um escore final que foi utilizado para caracterizar três fases do processo inflamatório.

Os resultados obtidos no estudo foram expressos por frequências e percentuais (variáveis qualitativas) ou por médias, medianas, valores mínimos, valores máximos e desvios-padrão (variáveis quantitativas). Para a comparação dos grupos e dos momentos de avaliação em relação a variáveis nominais dicotômicas foi usado o teste exato de Fisher. Estas comparações em 
relação a variáveis quantitativas foram feitas usando-se o teste não-paramétrico de Mann-Whitney. Valores de $p<0,05$ indicaram significância estatística

\section{RESULTADOS}

Durante o experimento não houve complicação clínica ou óbito de animais. Somente um rato do grupo Proceed 15 apresentou hematoma. Quanto à união entre a tela cirúrgica e a borda da ferida no grupo Ultrapro todos os animais apresentavam bordos bem coaptados enquanto no subgrupo Proceed 15 houve deiscência parcial em seis animais e no subgrupo Proceed 30 houve deiscência parcial em dois animais.

No subgrupo Ultrapro 15 houve um animal com infecção discreta e um com abcesso, e no subgrupo Ultrapro 30 houve um animal com abscesso. No subgrupo Proceed 15 houve presença de infecção discreta em dois animais e abscesso em um rato. Um animal apresentou hérnia visceral, do subgrupo Proceed 15 . No subgrupo Proceed 30 não houve infecção. Nenhum animal apresentou fístulas na cavidade abdominal.

Quanto à presença de aderências, usando a classificação de Nair et al. ${ }^{22}$, a Tabela 1 expressa melhor os resultados.

TABELA 1 - Comparação da presença de aderências nos subgrupos de animais avaliados no $15^{\circ}$ e $30^{\circ}$ dia do pós-operatório

\begin{tabular}{|c|c|c|c|c|}
\hline \multirow{2}{*}{$\begin{array}{c}\text { Presença de } \\
\text { aderências }\end{array}$} & \multicolumn{2}{|c|}{ Subgrupo } & \multicolumn{2}{|c|}{ Subgrupo } \\
\hline & Ultrapro 15 & Proceed 15 & Ultrapro 30 & Proceed 30 \\
\hline Grau 0 & $0 \%(n=0)$ & $0 \%(n=0)$ & $0 \%(n=0)$ & $0 \%(n=0)$ \\
\hline Grau 1 & $25 \%(n=2)$ & $25 \%(n=2)$ & $37,5 \%(n=3)$ & $75 \%(n=6)$ \\
\hline Grau 2 & $37,5 \%(n=3)$ & $50 \%(n=4)$ & $50 \%(n=4)$ & $25 \%(n=2)$ \\
\hline Grau 3 & $37,5 \%(n=3)$ & $12,5 \%(n=1)$ & $12,5 \%(n=1)$ & $0 \%(n=0)$ \\
\hline Grau 4 & $0 \%(n=0)$ & $12,5 \%(n=1)$ & $0 \%(n=0)$ & $0 \%(n=0)$ \\
\hline $\mathrm{p}$ & \multicolumn{2}{|r|}{1} & \multicolumn{2}{|c|}{1} \\
\hline Total & $100 \%$ & $100 \%$ & $100 \%$ & $100 \%$ \\
\hline
\end{tabular}

A Figura 4 mostra aderências encontradas no pósoperatório.

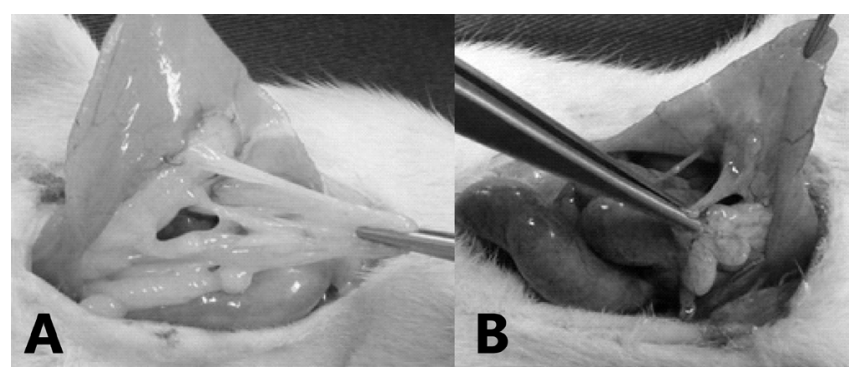

FIGURA 4 - Exemplos dos tipos de aderências encontradas: A - aderência grau 3 no subgrupo Ultrapro 15 e B - aderência grau 2 no subgrupo Proceed 15

A tensiometria mostrou que a ruptura do tecido tratado ocorreu sempre fora da região da tela, próximo á região da sutura.
Houve significamente maior força de ruptura no subgrupo Ultrapro 15 ( $P=0,038)$. A força de ruptura foi semelhante entre os subgrupos avaliados aos 30 dias de pós-operatório. Houve semelhança na avaliação tensiométrica na avaliação entre os subgrupos Ultrapro 15 e 30 e diferentes entre os subgrupos Proceed 15 e $30(P=0,007)$. As peças cirúrgicas com as telas Ultrapro e Proceed, tiveram avaliação de força de ruptura maior que a parede abdominal de rato virgem de tratamento. A Figura 5 mostra da força de ruptura.

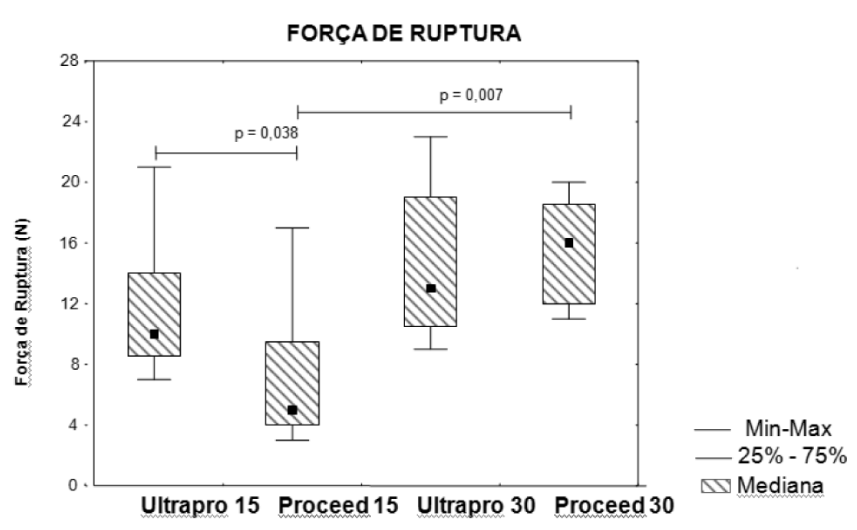

FIGURA 5 - Força de ruptura nos diversos tempos de avaliação do pós-operatório

$\mathrm{Na}$ avaliação microscópica, tanto os subgrupos Ultrapro 15 e 30 como os subgrupos Proceed 15 e 30 não apresentaram escore para processo inflamatório agudo. Os subgrupos Ultrapro 15 e Proceed 15 e os subgrupos Ultrapro 30 e Proceed 30 apresentaram escore para processo inflamatório subagudo e crônico semelhantes. A Figura 6 mostra as fases do processo inflamatório.

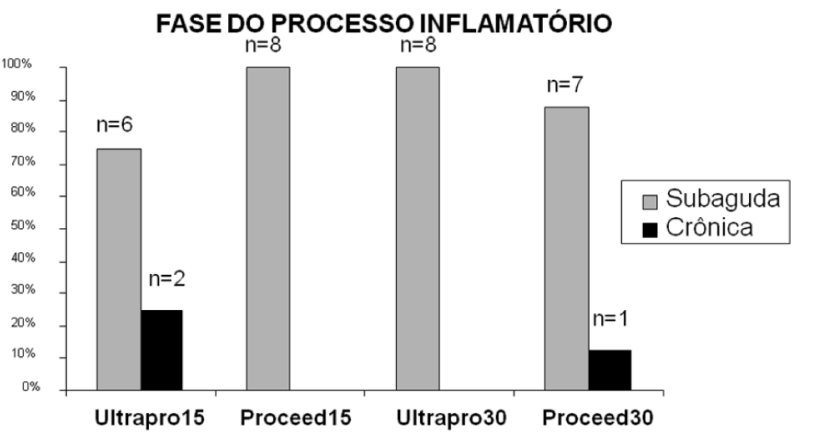

FIGURA 6 - Fases do processo inflamatório nos diversos grupos de estudo

Os subgrupos Ultrapro 15 e Proceed 15 e os subgrupos Ultrapro 30 e Proceed 30 apresentaram escore de inflamação igual.

O subgrupo Ultrapro 15 apresentou um escore de inflamação maior que o subgrupo Ultrapro 30, mostrando significância estatística com $p=0,028$, e os 
subgrupos Proceed 15 e Proceed 30 apresentaram escore de inflamação igual (Figura 7).

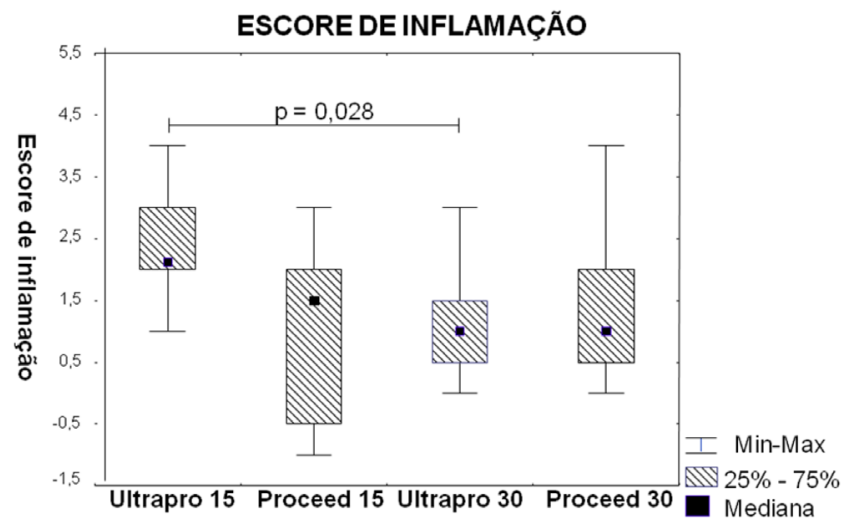

FIGURA 7 - Escore de inflamação nos diversos grupos de estudo

\section{DISCUSSÃO}

Este estudo faz parte de uma linha de pesquisa em cicatrização da parede abdominal com uso de telas do Programa de Pós-graduação em Princípios da Cirurgia. Telas têm sido usadas com frequência cada vez maior na prática cirúrgica com várias indicações. A escolha das utilizadas neste estudo foi definida pela atual procura de telas com possível disposição no interior da cavidade peritoneal. Entretanto, ela é um corpo estranho, sendo causa importante de formação de aderência peritoneal, apresentando as não absorvíveis ainda maiores risco de infecção $0^{4,28}$.

A tela ideal deve oferecer oclusão adequada e permanente do defeito da parede abdominal, com baixas taxas de infecção e de aderência, e não induzir formação de fístulas enterocutâneas. Utilizou-se a tela de polipropileno com polidioxanona e celulose oxidada regenerada (Proceed), elaborada para situações em que haja necessidade que a tela entre em contato com os órgãos da cavidade abdominal. A tela contém duas camadas absorvíveis que a separam dos tecidos, reduzindo a gravidade e a extensão de formação de aderências e impedindo a colonização de bactérias que podem levar às infecções, através da neoperitonização que ocorre na tela. A outra tela utilizada (Ultrapro) foi desenvolvida para dar suporte e reforço à parede abdominal com partes iguais de polipropileno e poliglecaprone, o que estimula cicatriz flexível e promove elasticidade multidirecional, oferecendo à parede abdominal dinâmica e fisiologia normais. No entanto não oferece barreira física entre a tela e as vísceras, sendo indicada preferencialmente sobre o peritôneo íntegro ${ }^{18}$.

A avaliação da união entre a tela cirúrgica e a borda da ferida abdominal mostrou que não houve diferença entre elas entre si e aos 15 e 30 dias, revelando que já aos 15 dias as duas telas apresentavam cicatrização adequada. Aos 15 dias elas apresentaram diferença significante em relação à união da tela cirúrgica com a borda da ferida, porém essa diferença não se perpetuou aos 30 dias.

Não houve significância estatística para a presença de infecção, sendo que a maioria dos animais não apresentou infecção. Estes dados são concordantes com a literatura pesquisada ${ }^{4}$. O emprego de técnicas de assepsia e antissepsia no pré e intra-operatório são realmente muito importantes para evitar que 0 ato cirúrgico seja caracterizado como contaminado. A infecção de ferida operatória é um dos fatores que prejudicam as diversas fases da cicatrização, quer seja nos mecanismos celulares ou humorais, sendo causa de recidiva da hérnia ${ }^{19}$.

Os resultados confirmam a eficácia de ambas as telas na prevenção da formação de aderências firmes com os órgãos intra-abdominais, dados coincidentes com a grande literatura revisada ${ }^{1}$.

Além disso, todos os ratos apresentaram algum grau de aderência, e, apesar de estatisticamente insignificante, o grupo Proceed apresentou mais casos de aderências leves enquanto o grupo Ultrapro de aderências discretas e moderadas. Os microporos servem como uma barreira à formação de aderências, enquanto os macroporos da tela de polipropileno promoveram a formação de aderências ${ }^{7}$. Deve haver uma barreira visceral entre a tela e as alças intestinais que dure no mínimo uma semana, pois este é o período de formação de aderências ${ }^{8}$. Mesmo as telas com barreira de proteção causam aderências ${ }^{23}$. A infusão intraperitoneal de substâncias líquidas juntamente com a colocação da tela com o intuito de formar uma barreira física não preveniu a formação de aderências ${ }^{29}$.

Boa parte dos estudos comparativos entre telas com as chamadas barreiras anti-aderência e telas sem esta proteção demonstraram significativamente menor formação de aderências no primeiro grupo ${ }^{8,11}$. Há exceções em que não encontrou diferença significativa na prevenção da formação de aderências com o uso de telas com barreiras anti-aderência e observou que a tela de ácido poliglicólico teve a mesma capacidade da tela de Parietex na prevenção da formação de aderências ${ }^{27}$. Estes resultados são discordantes com outros estudos 28,4 nos quais a formação de aderências foi significativamente mais severa e intensa com a tela de ácido poliglicólico absorvível quando comparada com a de polipropileno não absorvível.

Ambas as telas se equivaleram na efetividade de manutenção da força tênsil e integridade da parede ventral. Normalmente as telas macroporosas (polipropileno e poliéster) têm reação inflamatória menor, pois estão diretamente relacionadas à porosidade do material.

A avaliação tensiométrica verificou que o subgrupo Ultrapro 15 apresentou força tênsil maior que o subgrupo Proceed $15(P=0,038)$, havendo entre os subgrupos com 30 dias resultados semelhantes. Normalmente a tela de politetrafluoretileno expandida tem mais força tênsil que a de polipropileno, com incorporação tecidual precoce e baixo potencial de aderências, sendo mais indicadas para uso em operações abdominais. 
No presente estudo, o subgrupo Ultrapro 15 mostrou força tênsil semelhante ao subgrupo Ultrapro 30 e o subgrupo Proceed 30 mostrou maior força tênsil em relação ao subgrupo Proceed 15 , demonstrando aumento de sua força em tempo maior de pós-operatório.

Não houve nenhum achado de reação inflamatória aguda nos dois grupos. Já houve presença de reação inflamatória aguda nas telas usadas (poliéster/colágenopolietilenoglicol e submucosa intestinal suína) em coelhos $^{3}$, sendo que em 30 dias a primeira tela teve reação inflamatória menor que a segunda $(P=0,031)$; mas com 60 dias a reação inflamatória aguda foi semelhante nas elas. Os subgrupos Ultrapro 15 e Proceed 15 e os subgrupos Ultrapro 30 e Proceed 30 não apresentaram diferenças nas fases subaguda e crônica do processo inflamatório.

A formação de aderência é mais intensa com a tela de ácido poliglicólico quando comparada com a de polipropileno, e ocorre maior reação inflamatória durante a reabsorção da tela de ácido poliglicólico, que contém esta fina membrana justamente para evitar o contato das alças intestinais com a tela de polipropileno a ela sobreposta ${ }^{4,28}$. A tela Proceed (com polipropileno de baixa densidade), implantada no peritônio intacto de coelhos, comparada com a tela de PTFE expandida (DualMesh), PTFE com polipropileno (Composix, polipropileno de alta densidade), e polipropileno (Marlex, polipropileno de alta densidade) apresenta biocompatibilidade semelhante; já a formação da placa cicatricial foi menor na tela DualMesh que nas telas Composix e Marlex. Houve maior número de células inflamatórias ao redor da tela DualMesh. A tela Proceed apresentou maior potencial de aceitação em relação às demais ${ }^{16}$.

Estudos de cicatrização e próteses para reforço da parede abdominal ainda são recentes. Isto dificulta a comparação dos dados obtidos neste trabalho com a literatura por falta de estudos experimentais sobre o assunto. As perspectivas futuras apontam para um volume maior de trabalhos experimentais que envolvam cicatrização e o uso de telas cirúrgicas, e maior número de avaliações a longo prazo, possibilitando mais conhecimento no manejo destes materiais.

\section{CONCLUSÕES}

As telas são semelhantes nas variáveis analisadas.

\section{REFERÊNCIAS}

1. Araújo URMF, Czeczko NG, Ribas-Filho JM, Malafaia O, Budel VM, Balderrama CMSR, Zimmermann E, Dietz AU. Reparo intraperitoneal de defeitos da parede ventral do abdome com telas de poliéster com colágeno e polipropileno com ácido poliglicólico. Rev Col Bras Cir. 2009;36(3):241-9.

2. Baroncello JB, Czeczko NG, Malafaia O, Ribas-Filho JM, Nassif PAN, Dietz AU. O uso de telas Parietex $\AA$ e Surgisis ${ }^{\circledR}$ na correção de defeitos produzidos na parede abdominal de coelhos. Arq Gastroenterol. 2008;45(4):323-9.

3. Baycal A, Onat D, Rasa K, Renda N, Sayek I. Effects of polyglycolic acid and polypropylene meshes on postoperative adhesion formation in mice. World J Surg. 1997;21:579-83.

4. Brent DM, Broc LP, Harrison SP, Charles LB, Kent WK, Sing RF, Heniford BT. Assessment of adhesion formation to intra-abdominal 60 polypropylene mesh and polytetrafluoroethylene mesh. Journal of Surgical Research 2003;114:126-32.

5. Burger JWA, Halm JA, Wijsmuller AR, Ten Raa S, Jeekel J. Evaluation of new prosthetic meshes for ventral hérnia repair. Surg Endosc. 2006;20(8) 1320-5.

6. Demir U, Mihmanli M, Coskun H, Dilege E, Kalyoncu A, Altinli E, Gunduz B, Yilmaz B. Comparison of prosthetic materials in incisional hernia repair. Surg Today. 2005;35:223-7.

7. Ettinger JEMTM, Amaral PCG, Ázaro-Filho E, Ettinger-Junior E, SantosFilho PV, Fahel E. Reparo de hérnia de Grynfeltt com uso de tela de polipropileno sob anestesia local ABCD Arq Bras Cir Dig. 2006;19(1):368.

8. Johnson And Johnson. Proceed surgical mesh, 2007. Disponível em: www.herniasolutions.com/sites/default/files/pdf/PROCEED_Surgical_ Mesh.pdf. Último acesso em 14/06/2009.

9. Kapan S, Kapan M, Goksoy E, Karabicak I, Oktar H. Comparison of PTFE, pericardium bovine and fascia lata for repair of incisional hernia in rat model, experimental study. Hernia. 2003;7:39-43.

10. Kiudelis M, Jonciauskiene J, Deduchovas O, Radziunas A, Mickevicius A, Janciauskas D, Petrovas S, Endzinas Z, Pundzius J. Effects of different kinds of meshes on postoperative adhesion formation in the New Zealand White rabbit. Hernia. 2007;11(1):19-23.

11. Nair SK, Bhat AL, Aurora AL. Role of proteolitic enzyme in the prevention of postoperative intraperitoneal adhesions. Arch Surg 1974;108:84953.

12. Novitsky YW, Harrell AG, Cristiano JA, Paton BL, Norton $\mathrm{HJ}$, Peindl RD, Kercher KW, Heniford BT. Comparative evaluation of adhesion formation, strenght of ingrowth, and textile properties of prosthetic meshes after long-term intra-abdominal implantation in a rabbit. J Surg Res. 2007;140(1):6-11.

13. Pascual G, Rodríguez M, Gomez-Gil V, García-Honduvilla N, Buján J, Bellón JM. Early tissue incorporation and collagen deposition in lightweight polypropylene meshes: bioassay in an experimental model of ventral hernia. Surgery. 2008;144(3):427-35.

14. Schug-Pass C, Tamme C, Sommerer F, Tannapfel A, Lippert H, Köckerling

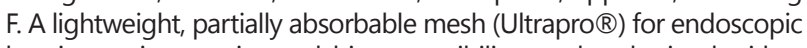
hernia repair: experimental biocompatibility results obtained with a porcine model. Surg Endosc. 2008;22(4):1100-6.

15. Schulz DD, Czeczko NG, Malafaia O, Schulz GJ, Czeczko LE, Garcia LS, Dietz UA. Evaluation of healing prosthetic materials polyester mesh resorbable film and collagen elastin matrix /polypropylene used in rabbits abdominal wall defects. Acta Cir Bras. 2009;24(6):476-83.

16. Sher W, Pollack D, Paulides CA, Matsumoto T. Repair of abdominal wall defects: Gore-Tex vs. Marlex graft. Am Surg. 1980;46(11):618-23.

17. Tyrell J, Silberman H, Chandrasoma P, Niland J, Shull J. Absorbable versus permanent mesh in abdominal operations. Surg Gynecol Obstet. 1989 Mar;168(3):227-32.

18. van 't Riet $M$, de Vos van Steenwijk PJ, Bonthuis $F$, Marquet RL, Steyerberg EW, Jeekel J, Bonjer HJ. Prevention of adhesion to prosthetic mesh: comparison of different barriers using an incisional hernia model. Ann Surg. 2003;237(1):123-8. 